\title{
Local magnitude estimate at Mt. Etna
}

\author{
Salvatore D'Amico and Vincenza Maiolino \\ Istituto Nazionale di Geofisica e Vulcanologia, Sezione di Catania, Italy
}

\begin{abstract}
In order to verify the duration magnitude $M_{D}$ we calculated local magnitude $M_{L}$ values of 288 earthquakes occurring from October 2002 to April 2003 at Mt. Etna. The analysis was computed at three digital stations of the permanent seismic network of Istituto Nazionale di Geofisica e Vulcanologia of Catania, using the relationship $M_{L}=\log A+a \log \Delta-b$, where $A$ is maximum half-amplitude of the horizontal component of the seismic recording measured in $\mathrm{mm}$ and the term $«+a \log \Delta-b »$ takes the place of the term $«-\log A_{0} »$ of Richter relationship. In particular, $a=0.15$ for $\Delta<200 \mathrm{~km}, b=0.16$ for $\Delta<200 \mathrm{~km}$. Duration magnitude $M_{D}$ values, moment magnitude $M_{W}$ values and other local magnitude values were compared. Differences between $M_{L}$ and $M_{D}$ were obtained for the strong seismic swarms occurring on October 27, during the onset of 2002-2003 Mt. Etna eruption, characterized by a high earthquake rate, with very strong events (seismogram results clipped in amplitude on drum recorder trace) and high level of volcanic tremor, which not permit us to estimate the duration of the earthquakes correctly. $M_{L}$ and $M_{D}$ relationships were related and therefore a new relationship for $M_{D}$ is proposed. Cumulative strain release calculated after the eruption using $M_{L}$ values is about $1.75 \mathrm{E}+06 \mathrm{~J}^{1 / 2}$ higher than the one calculated using $M_{D}$ values.
\end{abstract}

Key words Mt. Etna - local magnitude - volcano seismicity

\section{Introduction}

In order to know the size of an earthquake without considering the produced effects, Richter proposed the definition of magnitude and related it to the maximum amplitude of the ground displacement.

The «local magnitude» $M_{L}$ (Richter, 1935), is defined with the relationship

$$
M_{L}=\log A-\log A_{0}
$$

where $A$ is the maximum amplitude peak to peak measured in $\mathrm{mm}$, recorded by a standard WoodAnderson seismometer with natural period of $0.8 \mathrm{~s}$, magnification 2800 and damping factor

Mailing address: Dr. Salvatore D'Amico, Istituto Nazionale di Geofisica e Vulcanologia, Sezione di Catania, Piazza Roma 2, 95123 Catania, Italy; e-mail: damico@ct.ingv.it
0.8 . The quantity «- $\log A_{0} »$ is defined empirically with respect to a reference earthquake, which describes the variation of maximum amplitude $(A)$ of the event related to the epicentre distance $(\Delta)$. Geometric spreading, elastic attenuation and scattering of seismic waves, therefore, influence the amplitude decay. Richter fixed $A_{0}(\Delta)$ level at $1 \mu \mathrm{m}$ for a distance of $100 \mathrm{~km}$.

Later, to evaluate magnitude in a more practical approach, principally when the recording of strong earthquakes is clipped in amplitude, empiric relationships were developed using the duration of the seismic event by Solov'ev (1965), Tsumara (1967) and many other authors.

In the last twenty years, earthquake magnitudes were always estimated at Mt. Etna volcano with the duration of the seismic event using appropriate relationships.

Caltabiano et al. (1986), used the Serra Pizzuta Calvarina (ESP) station of Permanent Seismic Network run by Istituto Internazionale di Vulcanologia (IIV) of the CNR of Catania, for the following relationship:

$$
M_{D}=-1.367+2.068 \log \tau+0.212 \log \Delta
$$


where $\tau$ is the duration time of the event in seconds and $\Delta$ is hypocentre distance in $\mathrm{km}$.

These authors studied a dataset of 70 earthquakes with hypocentre distance within $11 \mathrm{~km}$ for an extremely local relationship. The difference between $P$ - and $S$-waves arrival time was used to estimate the hypocentre distance. Istituto Nazionale di Geofisica e Vulcanologia (INGV) supplied the reference magnitude.

Later, Cardaci and Privitera (1996) introduced a new relationship to calculate duration magnitude for the permanent seismic network of IIV, based on methodology proposed by Real and Teng (1973). The dataset analysed by the authors was composed of 198 earthquakes recorded between 1990 and 1994, the reference magnitude, supplied by Istituto Nazionale di Geofisica e Vulcanologia, is comprised between 2.0 and 3.5 and was estimated on stations far from Mt. Etna using the duration of event recording.

\section{Magnitude of Mt. Etna earthquakes}

At present the Mt. Etna Permanent Seismic Network, of the Istituto Nazionale di Geofisica e
Vulcanologia, Sezione di Catania (INGV-CT), consists of 30 stations. The seismic signals are acquired continuously and are transmitted via radio to Centro Acquisizione Dati Sismici (CADS) of the INGV-CT where they are digitally saved with a sampling rate of $125 \mathrm{~Hz}$.

As routine, the magnitude of earthquakes recorded by the Permanent Seismic Network of (INGV-CT) is calculated using the duration of the seismic event recorded on a drum recorder using the relationship of Caltabiano et al. (1986). The reference station was ESP until 1999 and thereafter EMA.

Usually, when an event is «truncated» by the occurrence of another seismic event, the duration is estimated by amplitude decay.

Recent seismic swarms, which occurred during the opening of the eruptive fractures of the last eruptions (2001 and 2002-2003), were characterized by a high earthquake rate, with very strong events (seismogram results clipped in amplitude on drum recorder trace) and high level of volcanic tremor. Figure 1 shows the seismogram of the seismic swarm during the onset of 20022003 Mt. Etna eruption. From 00:27 GMT of 27.10.2002, it was very difficult to estimate the

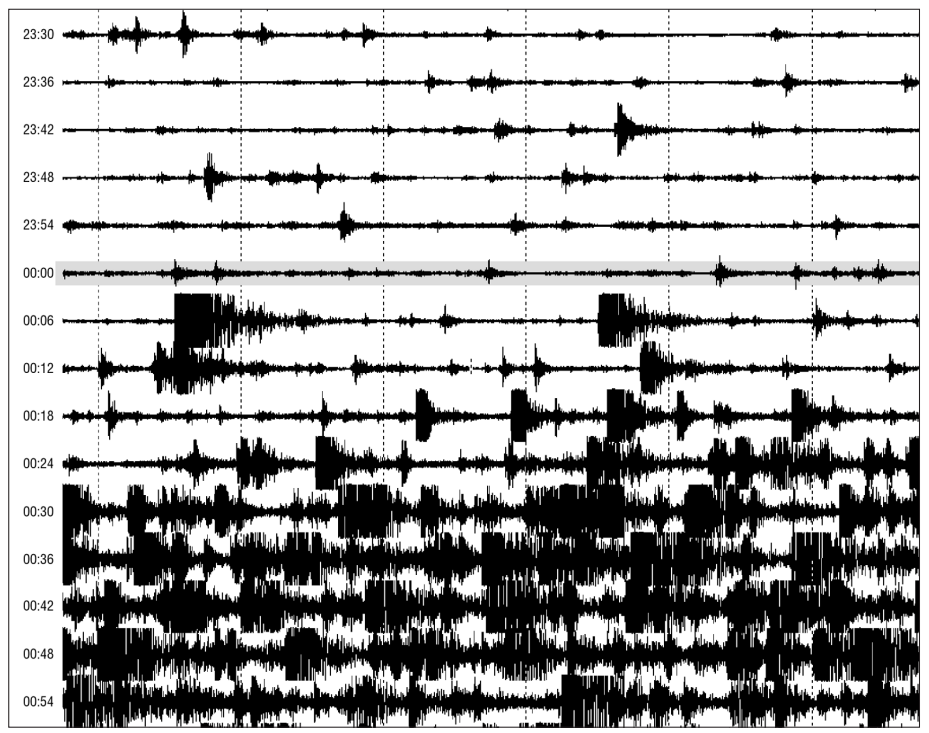

Fig. 1. Seismogram at EMA station recorded between 26.10.2002 at 23:30 GMT and 27.10.2002 at 00:59 GMT. 
duration of each earthquake and the related magnitude. In order to verify the duration magnitude calculated for the earthquakes of 2002-2003 Mt. Etna eruption, we worked to simulate a WoodAnderson seismometer and then computed local magnitude with the relationship (Lahr, 1999)

$$
M_{L}=\log A+a \log \Delta-b
$$

where $A$ is maximum half-amplitude of the horizontal component of the seismic recording measured in $\mathrm{mm}$ and the term $«+a \log \Delta-b »$ takes the place of the term $«-\log A_{0} »$ of Richter relationship. In particular, $a=0.15$ for $\Delta<200$ $\mathrm{km}, b=0.16$ for $\Delta<200 \mathrm{~km}$. The approximation for this parametric form is smaller than 0.2 in comparison with correction values for source-receiver distance from Richter's table (Di Grazia et al., 2001). $\Delta$ is hypocentre distance in $\mathrm{km}$ and is calculated by the relationship

$$
\Delta=\sqrt{D^{2}+(H+Q)^{2}}
$$

where $D$ is epicentre distance in $\mathrm{km}, H$ is the depth of the earthquake in $\mathrm{km}$ b.s.l. and $Q$ is the altitude of the station in $\mathrm{km}$ a.s.l.

\section{The 2002-2003 Mt. Etna eruption}

In the night between October 26 and 27, 2002 a seismic swarm occurred in the central upper part of Mt. Etna. It was the start of a new eruption of Etna that formed fissures on both the NE and $\mathrm{S}$ flanks of the volcano. On October 27 eruptive fissures opened on the higher flank of the volcano produced high fire fountains, evolving into ash columns (Calvari et al., 2004). On October 29, numerous tectonic structures on the eastern flank of the volcano were activated through seismic swarms, causing serious damage to S. Venerina village and in the neighbouring areas on Mt. Etna's eastern flank (Azzaro and Mostaccio, 2003; Azzaro and Scarfì, 2003).

The eruption gave rise to a huge lava emission from both fracture fields and powerful explosive activity from the southern one. After 94 days the eruption ended on January 28, 2003.

Much of the seismicity occurred during the first day of the eruption, while the remarkable clusters of earthquakes on the southeastern flank are largely related to the 29 October seismic crisis.

An overall number of 862 earthquakes $\left(M_{D} \geq\right.$ $\geq 1$ ) were recorded by the permanent seismic network run by INGV-CT. Maximum magnitude observed was 4.4 and 56 earthquakes exceeded $M_{D}=3.0$.

\section{Data analysis}

The dataset used in this work is composed of 288 earthquakes occurring between October 2002 and April 2003 (fig. 2). The magnitude $\left(M_{D}\right)$ of these earthquakes is between 1.0 and 4.4. The focal depths of the earthquakes are concentrated within the uppermost $5 \mathrm{~km}$ below sea level (b.s.l.).

To study the relationship for the local magnitude we used the digital stations ESP, EMV and EMG. The first is equipped with a Lennartz LE-3D/20s seismometer; the others (EMV and EMG) are equipped with Lennartz LE-3D/1s sensors. The former is a broadband seismometer with corner frequency $\omega_{0}=0.05 \mathrm{~Hz}(20 \mathrm{~s})$, output voltage $k=1000 \mathrm{~V} / \mathrm{m} / \mathrm{s}$ and damping $h=$ $=0.707$; the LE-3D/1s have a corner frequency $\omega_{0}=1.00 \mathrm{~Hz}$, output voltage $k=400 \mathrm{~V} / \mathrm{m} / \mathrm{s}$ and damping $h=0.707$.

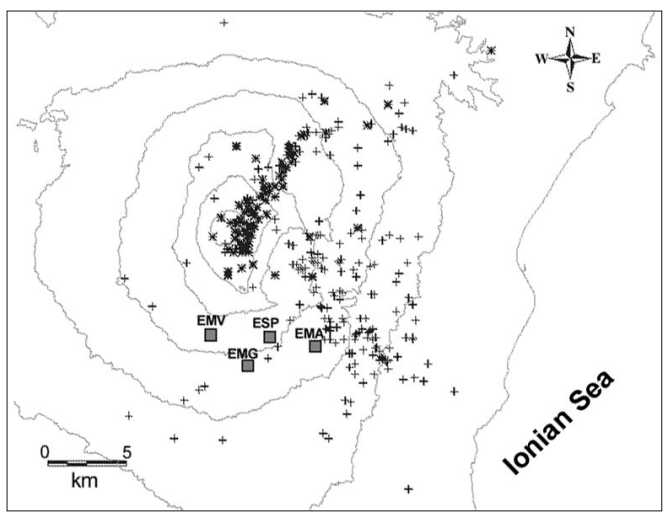

Fig. 2. Mt. Etna map. The grey squares indicate the stations used to calculate the local magnitude $\left(M_{L}\right)$ or the duration magnitude $\left(M_{D}\right)$. The earthquakes epicentres are indicated with crosses; earthquakes occurring on October 26 and 27, 2002 are indicated with asterisks. 
Analytic locations of the earthquakes were performed by HYPOELLIPSE routine (Lahr, 1999), using a onedimensional VP velocity model with 7 plane-parallel layers (Hirn et al., 1991) as described in table I.

Table I. One-dimensional $V_{P}$ velocity model.

\begin{tabular}{cc}
\hline \hline Top layer $(\mathrm{km})$ & $V_{P}$ velocity $(\mathrm{km} / \mathrm{s})$ \\
\hline 0.00 & 3.00 \\
0.50 & 3.59 \\
2.00 & 4.00 \\
4.00 & 4.80 \\
6.00 & 5.59 \\
12.00 & 6.50 \\
30.00 & 8.00 \\
\hline
\end{tabular}

The errors on the epicentre and hypocentre coordinates are smaller than $2 \mathrm{~km}$.

\subsection{Methodology}

For each selected earthquake (fig. 3a), we calculated a Discrete Fourier Transformation (DFT) on the horizontal components of the seismic record (fig. 3b). The velocity response curve of the seismometer (fig. 3c) is defined by the relationship

$$
E(\omega)=\frac{k \omega^{2}}{\left(\omega_{0}^{2}-\omega^{2}\right)+2 i h \omega_{0} \omega}
$$

where $k$ is the sensitivity of the transducer in $\mathrm{V} / \mathrm{m} / \mathrm{s}, \omega$ is the angular frequency, $\omega_{0}$ is the natural period, and $h$ is the damping. This kind of (a)

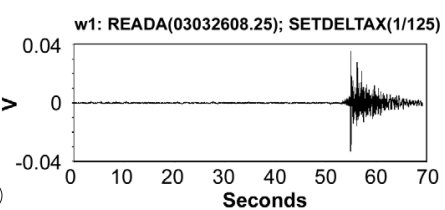

(C)

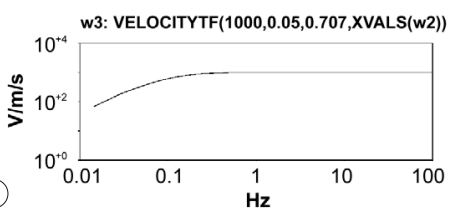

(e)

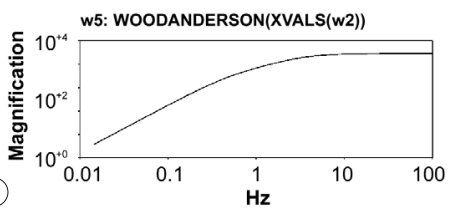

(g)

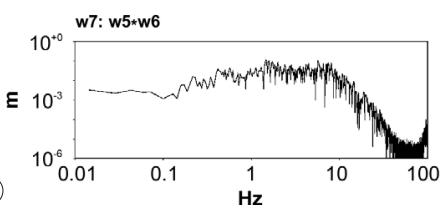

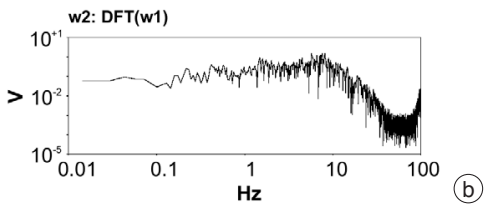
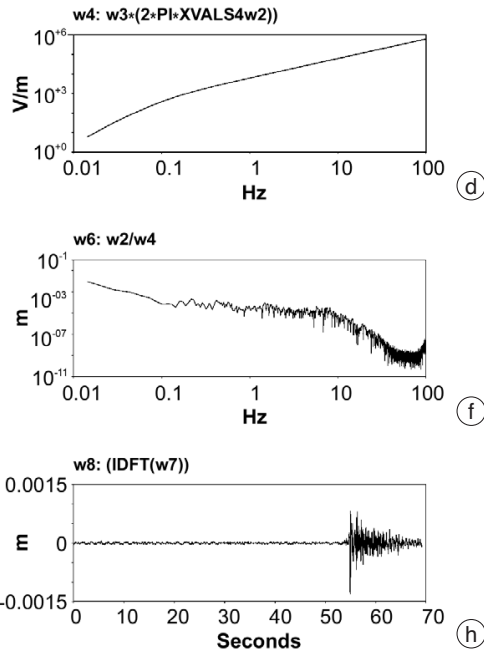

Fig. 3a-h. The DaDisp worksheet used to simulate a seismic signal recorded by standard Wood-Anderson seismometer. a) Velocity seismic signal recorded by geophone; b) DFT of velocity seismic signal; c) velocity response curve of geophone; d) displacement response curve of geophone; e) Wood-Anderson response curve; f) velocity spectrum divided by displacement response curve; g) corrected spectrum multiplied by Wood-Anderson response curve; h) Wood-Anderson simulated seismic signal. 
sensor has no calibration coil and it is very difficult to know the real technical parameters, for this reason we used the data reported in the factory datasheet.

Velocity response curve was transformed in displacement response curve (fig. 3d), by multiplying it for the angular velocity $\omega$ (Bath, 1974) before correcting the velocity spectrum.

Multiplying the response curve of a standard Wood-Anderson seismometer (fig. 3e), with static magnification 2800 , damping 0.8 and natural period $0.8 \mathrm{~s}$ (Richter, 1935), with the correct displacement spectrum (fig. 3f) we obtained signal of fig. 3g. The simulated Wood-Anderson seismogram (fig. 3h) was obtained with DFT inverse of fig. $3 \mathrm{~g}$.

We used the software DaDisp 4.0 to analyse the digital signals on the whole seismic record. The half-amplitude $A$, used to obtain the magnitude, was calculated as a mean of N-S and E-W components.

Urhammer and Collins (1990), verified that the 2800 static magnification is determined by the manufacturer and it is not the static magnification determined from measurements of the natural period and tilt-sensitivity.

They suggest using the value of approximately 2080. Assuming a static magnification of
2800 (as has been common practice, e.g., Bakun et al., 1978; Kanamori and Jennings, 1978; Luco, 1982; Del Pezzo and Petrosino, 2001) will lead to a systematic over estimation of $M_{L}$ by an average of $0.13 M_{L}$ units (Urhammer and Collins, 1990).

We decided to apply the 2800 static magnification value to this work because it is more widely used in common practice and the calculated $M_{L}$ is comparable with $M_{L}$ calculated from stations of different networks.

\section{Results}

\subsection{Comparison with duration magnitude}

Figure 4 shows the magnitude values $M_{L}$ calculated at ESP compared with the corresponding magnitude values $M_{D}$. The grey squares indicate earthquakes occurring between October 26 and 27. $M_{D}$ values are overestimated respect to $M_{L}$ and are scattered for about 1.0 units on $M_{D}$ axis below $M_{L}=2.2$. This data scattering is due to error on estimate of earthquake duration. Moreover, grey squares dataset shows a different trend with respect to white squares dataset.

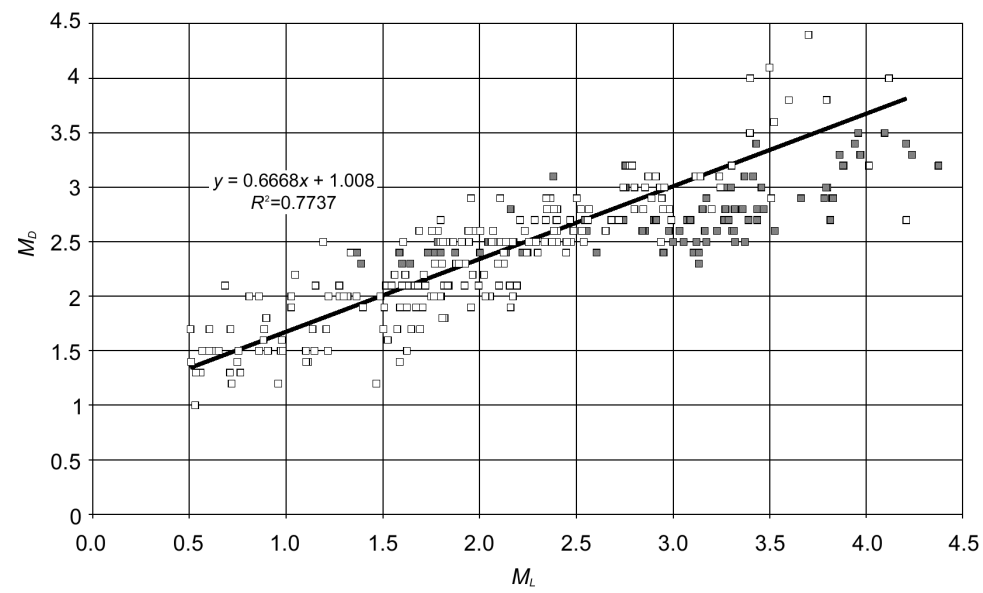

Fig. 4. Comparison between $M_{D}$ and $M_{L}$ at ESP station. The grey squares indicate the earthquakes occurring from October 26 at 00:27 GMT and October 27; the thick black line of linear regression and relative equation refers to white squares dataset. 
A linear regression between $M_{D}$ and $M_{L}$ values was performed, excluding the October 26 and 27 dataset. The relationship obtained is

$$
M_{D}=0.6668 M_{L}+1.008
$$

with coefficient of variation of the regression $R^{2}=0.7737$.

Figure 5 shows the magnitude $M_{L}$ (at ESP station) with respect to time origin. Earthquakes with higher magnitude were recorded

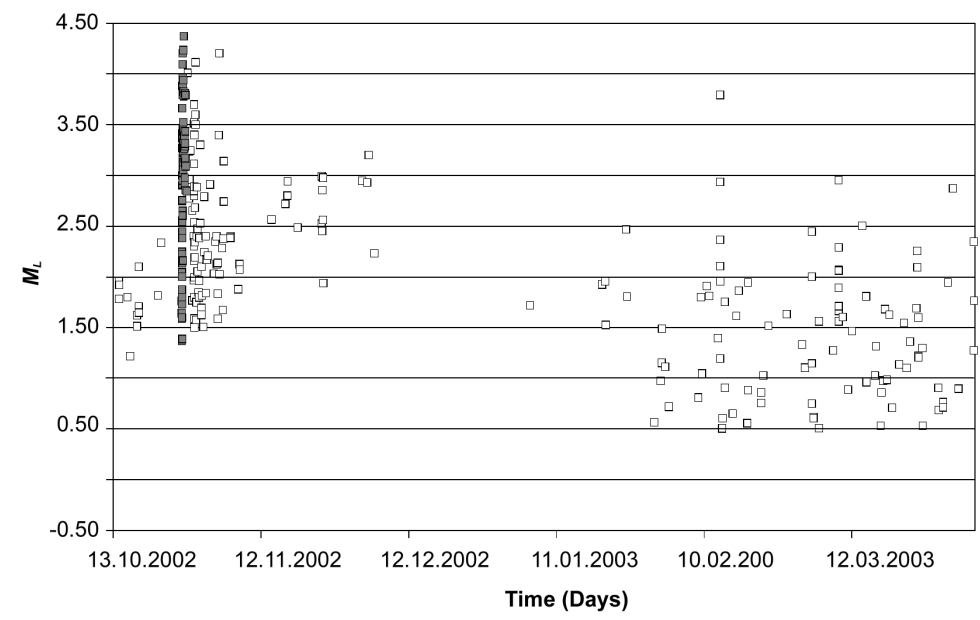

Fig. 5. $M_{L}$ calculated at ESP station with respect to time origin. The grey squares indicate the earthquakes occurring on October 26 at 00:27 GMT and October 27.

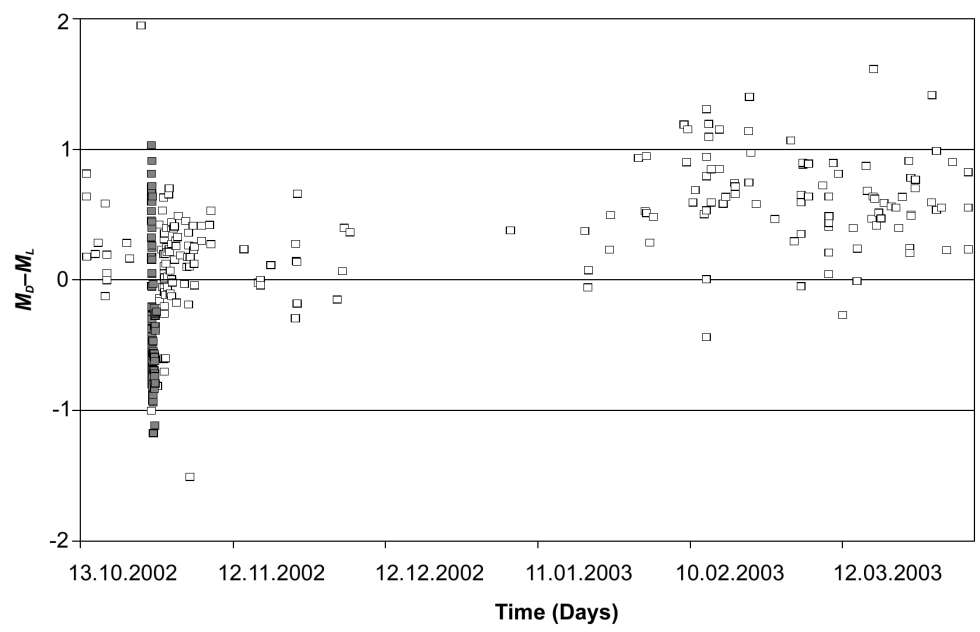

Fig. 6. Difference $M_{D}-M_{L}$ (at ESP station) with respect to time origin. The grey squares indicate the earthquakes occurring on October 26 at 00:27 GMT and October 27. 


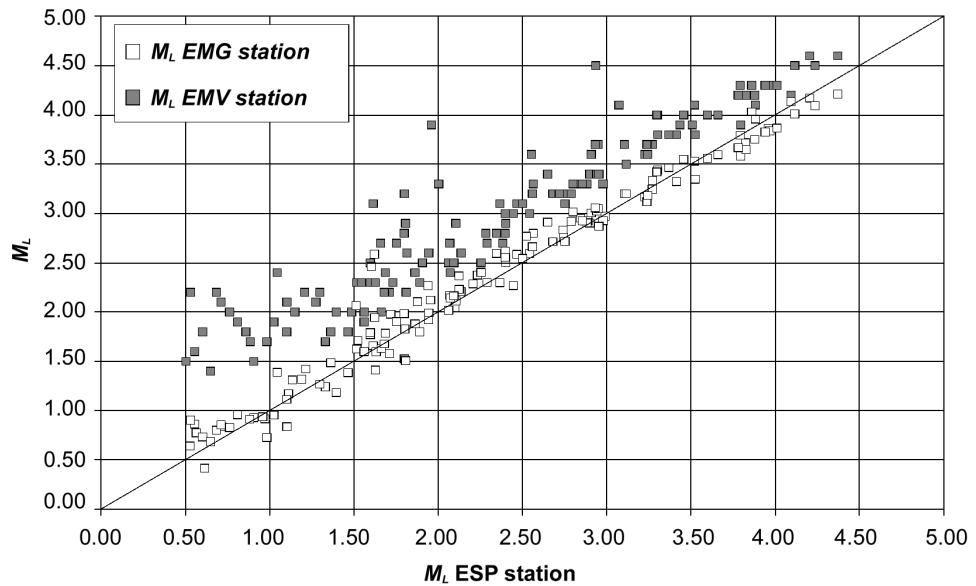

Fig. 7. Relation between $M_{L}$ estimated at EMG station (white), at EMV station (grey) and at ESP station.

during the opening of the eruptive fractures (October 26 and 27, grey squares), while the earthquakes with the smaller magnitude were recorded only at the end of the eruption.

We may assume that the estimate of the magnitude $M_{D}$ on October 26 and 27 is not perfectly correct. In fact, as mentioned above, when there are many earthquakes in a short time, or when there is higher amplitude of the volcanic tremor, it is more difficult to read the real duration of the earthquake. Moreover, the strongest earthquakes recorded on the drum recorder, show clipped amplitude (see fig. 1). For these reasons it is very difficult to estimate the amplitude decay. This amplitude saturation infers only the trace drawn by the drum recorder pen and it does not affect the digitally recorded signal.

This theory is in agreement with fig. 6, where the difference $M_{D}-M_{L}$ (at ESP station) with respect to time origin is shown. The graph again highlights $M_{D}$ higher than $M_{L}$ except for earthquakes on October 26 and 27, 2002. Figure 7 compares the $M_{L}$ values, at EMG and EMV, with $M_{L}$ values at ESP; there is a good agreement between ESP and EMG values; the EMV values have a good agreement above $M_{L}>$ $>1.5$, but are overestimated by about 0.5 .

Figure 8a,b shows velocity and Wood-Anderson simulated traces of two seismic events. The signal-noise ratio at EMV station is smaller than other two stations, both during the eruptive phase (fig. 8a), with a high level of volcanic tremor, and at the end of the eruption (fig. 8b).

We think that EMV values are affected by site-effect overestimating magnitude values with respect to ESP and EMG values. This siteeffect is more evident for earthquakes with $M_{L}>1.5$, while for the other earthquakes the signal-noise ratio at EMV station is very small and it is not possible to estimate the maximum amplitude peak to peak clearly.

Following Gasperini (2002), we proceeded to a calibration of a new relation of $M_{D}$ on the basis of the dataset of $M_{L}$ magnitudes excluding the October 26 and 27 earthquakes, and of the duration values. In our analysis we computed the coefficients of a linear regression, equivalent to the Caltabiano et al. (1986) formula, of $M_{L}$ with both $\log \tau$ and $\log \Delta$ as independent variables. This gives

$M_{L}=(2.477 \pm 0.099) \log \tau+$

$+(0.464 \pm 0.172) \log \Delta-(2.655 \pm 0.227)$

with coefficient of variation of the regression $R^{2}=0.770$.

The linear regression computed is nevertheless affected by errors on duration estimate. In order to reduce the errors in the coefficients we performed another linear regression excluding data with residuals obtained from previous re- 

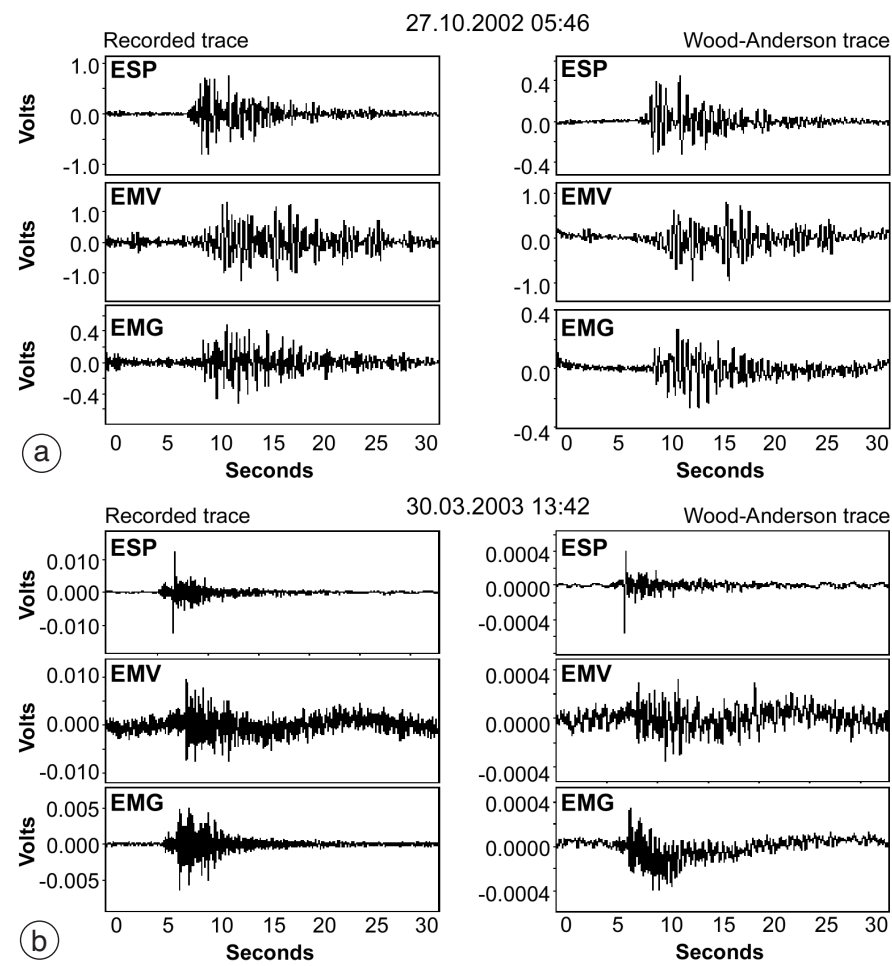

Fig. 8a,b. 27.10.2002 at 05:46 GMT (a) and 03.03.2003 at 13:42 GMT (b) events recorded at ESP, EMV and EMG station. Left: traces acquired by seismic station in velocity; right: Wood-Anderson simulated traces.

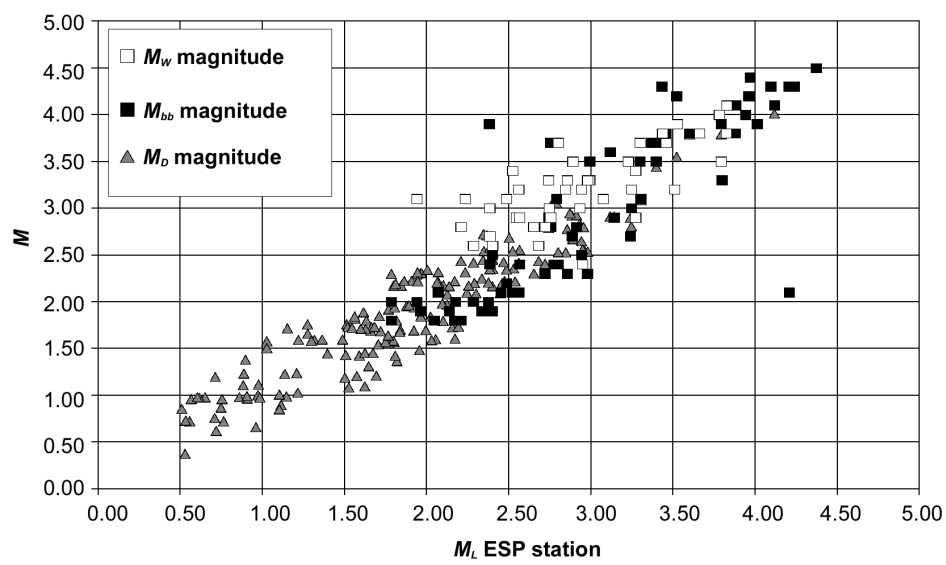

Fig. 9. Relation between Moment magnitude $M_{W}$ (white squares), local magnitude $\left(M_{b b}\right)$ at broadband stations of MedNet (black squares), duration magnitude $M_{D}$ (grey triangles) calculated with the new relation and local magnitude $M_{L}$ at ESP station. 
gression greater of 0.25 units. The result is

$M_{L}=(2.494 \pm 0.073) \log \tau+$

$+(0.438 \pm 0.131) \log \Delta-(2.644 \pm 0.176)$

with coefficients of variation of the regression $R^{2}=0.873$.

\subsection{Comparison with magnitude values calculated using different methods}

Figure 9 plots $M_{D}$ values obtained from the new Duration-Magnitude scale (grey triangles) versus $M_{L}$ values. We also compared the local magnitude values estimated by the broadband stations of MedNet seismic network located in Sicily (black squares) and the moment magnitude estimated by seismic moment (white squares).

The magnitude $\left(M_{b b}\right)$ is calculated using the Richter relationship (1935) as a mean value from the horizontal components of the AIO and VAE stations (MEDNET, 2003).
The moment magnitude $\left(M_{W}\right)$ is calculated with Kanamori's relationship (Lay and Wallace, 1995)

$$
M_{W}=\left(\frac{\log M_{0}}{1.5}\right)-10.73
$$

where $M_{0}$ (Keilis-Borok, 1957) is seismic moment obtained by source parameters (Brune, 1970) at station ESP (Giampiccolo et al., 2003).

A good agreement is shown between $M_{L}$ values and new $M_{D}$ values. Moreover, we observe that, with a few exceptions, $M_{b b}$ values agree with $M_{L}$ values, and $M_{W}$ values agree with $M_{L}$ values for $M_{L}>2.7$.

\section{Strain release}

Figure 10 shows the cumulative strain release (Joule ${ }^{1 / 2}$ ) calculated by $M_{D}$ (thin line) and by $M_{L}$ values (thick line). The strain release value of the earthquake was obtained as the square root of the energy $E$ in Erg, which is estimated with Richter's relationship (1958)

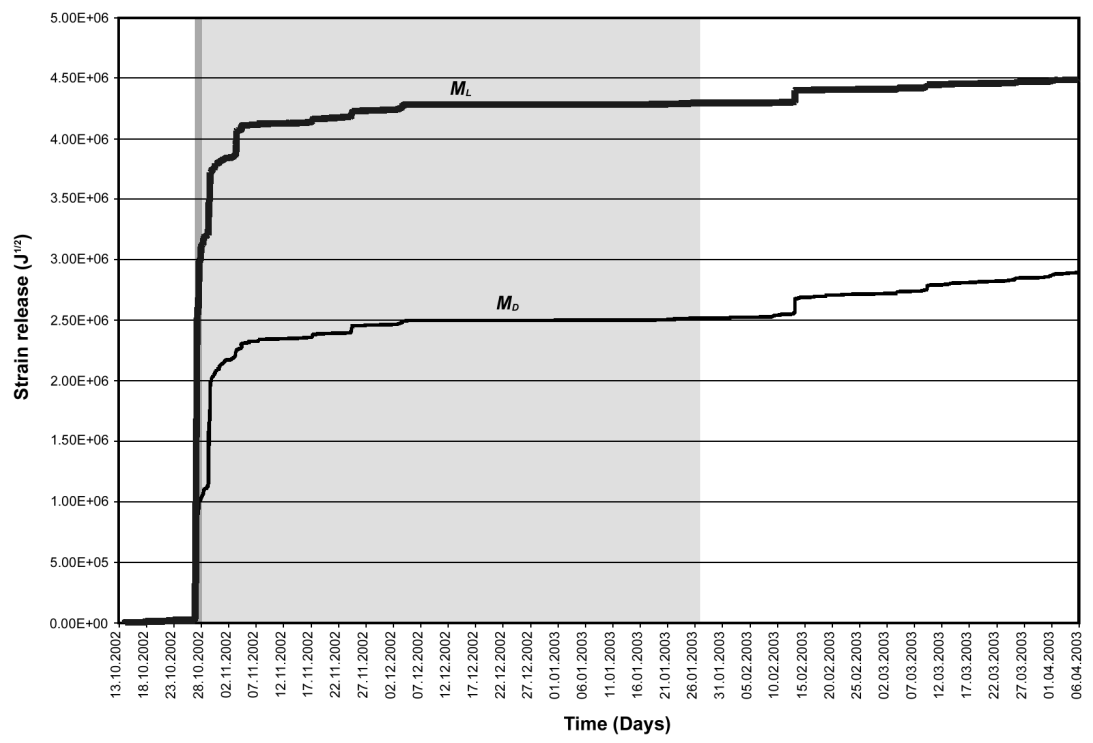

Fig. 10. Cumulative energy strain release in the period October 14, 2002-April 5, 2003. Thin line represents strain release calculated by $M_{D}$ values, while thick line represents strain release calculated by $M_{L}$ values. Dark grey area highlights October 27 day and light grey area the eruptive period (October 28, 2002-January 27, 2003). 
$\log E=9.9+1.9 M-0.024 M^{2} \quad$ for $M \leq 4.5$

$\log E=11.8+1.5 M$

for $M>4.5$

where $M$ is the magnitude.

In the figure two periods are highlighted: the former (dark grey) indicates the seismic swarm occurring on October 27, corresponding to the opening of the eruptive fractures, while the latter (light grey) represents the eruption beginning on October 28 and ending on January 27.

A marked difference of cumulative strain release between $M_{D}$ and $M_{L}$ series is observable during the seismic sequence of October 27, due to the underestimated $M_{D}$ values as seen in figs. 4 and 6 . In the later period, where it is easier to estimate the duration of the earthquakes, the strain release values are comparable. After the eruption the overall difference of strain release calculated from $M_{L}$ values and from $M_{D}$ values is about $1.75 \mathrm{E}+06 \mathrm{~J}^{1 / 2}$.

\section{Conclusions}

The aim of this work was to estimate local magnitude by simulating a Wood-Anderson seismometer and compare the results with different magnitude scales.

$M_{L}$ values calculated at ESP and EMG are absolutely coherent, while EMV values are overestimated by 0.5 .
$M_{L}$ values compared with $M_{b b}$ and $M_{W}$ values show a good correlation.

$M_{D}$ values seem to be overestimated. Although it is difficult obtaining reliable $M_{D}$ values with this dataset for the strongest earthquakes, corresponding to the opening of the eruptive fracture a try to recognise a relationship between $M_{L}$ and $M_{D}$ was performed. A new duration-magnitude scale is proposed.

The dataset used and the $M_{L}$ values calculated are reported in the Appendix.

In conclusion, it is remarkable that in environments with high seismic noise, such as Mt. Etna volcano, the magnitude estimates based on the measurement of the ground amplitude are more reliable and that some care must be taken in using a magnitude scale based on coda duration for low values of magnitude when the noise level is high. As the correct estimate of seismic parameters is important for a quantitative evaluation of volcano dynamics, the Wood-Anderson magnitude scale should be routinely determined together with duration-magnitude in volcano monitoring. A software program to reach these objectives is in preparation at this time.

\section{Acknowledgements}

We are grateful to F. Mulargia and S. Castellaro for their constructive criticism that strongly improved the early version of this paper.

Appendix. Dataset used for the analysis and $M_{L}$ values.

\begin{tabular}{cccc|cccc}
\hline \hline Time & Origin & $M_{D}$ & $M_{L}$ & Time & Origin & $M_{D}$ & $M_{L}$ \\
\hline 14.10 .2002 & 03.34 .14 & 2.6 & 2.0 & 18.10 .2002 & 04.06 .29 & 1.9 & 1.7 \\
14.10 .2002 & 03.55 .16 & 2.6 & 1.8 & 18.10 .2002 & 04.47 .12 & 1.7 & 1.6 \\
14.10 .2002 & 04.40 .30 & 2.1 & 1.9 & 22.10 .2002 & 01.39 .07 & 2.1 & 1.8 \\
15.10 .2002 & 21.22 .13 & 2.0 & 1.8 & 22.10 .2002 & 16.29 .15 & 2.5 & 2.3 \\
16.10 .2002 & 10.10 .21 & 1.5 & 1.2 & 26.10 .2002 & 21.35 .54 & 2.4 & 1.8 \\
17.10 .2002 & 19.28 .58 & 2.1 & 1.5 & 26.10 .2002 & 21.46 .51 & 2.3 & 1.6 \\
17.10 .2002 & 19.41 .44 & 1.5 & 1.6 & 26.10 .2002 & 21.55 .39 & 2.4 & 1.6 \\
18.10 .2002 & 04.04 .15 & 2.1 & 2.1 & 26.10 .2002 & 22.04 .57 & 2.4 & 1.4 \\
\hline
\end{tabular}


Appendix (continued).

\begin{tabular}{|c|c|c|c|c|c|c|c|}
\hline Time & Origin & $M_{D}$ & $M_{L}$ & Time & Origin & $M_{D}$ & $M_{L}$ \\
\hline 26.10 .2002 & 22.17 .57 & 2.3 & 1.6 & 27.10.2002 & 01.37 .11 & 2.6 & 3.0 \\
\hline 26.10 .2002 & 22.25 .38 & 2.5 & 1.8 & 27.10 .2002 & 01.38 .28 & 2.8 & 3.4 \\
\hline 26.10 .2002 & 22.28 .25 & 2.4 & 1.9 & 27.10.2002 & 01.42 .21 & 2.7 & 3.3 \\
\hline 26.10 .2002 & 22.33 .40 & 2.4 & 2.2 & 27.10 .2002 & 01.53 .01 & 2.5 & 3.2 \\
\hline 26.10 .2002 & 22.40 .45 & 2.5 & 2.2 & 27.10 .2002 & 02.15 .17 & 2.5 & 3.4 \\
\hline 26.10 .2002 & 22.51 .16 & 2.5 & 2.0 & 27.10 .2002 & 02.18 .29 & 3.2 & 3.9 \\
\hline 26.10 .2002 & 23.13 .08 & 2.4 & 2.2 & 27.10 .2002 & 02.29 .28 & 3.5 & 4.0 \\
\hline 26.10 .2002 & 23.22.29 & 2.7 & 2.7 & 27.10 .2002 & 02.39 .10 & 3.3 & 4.0 \\
\hline 26.10 .2002 & 23.27 .48 & 2.4 & 1.8 & 27.10 .2002 & 02.42 .11 & 3.4 & 4.2 \\
\hline 26.10 .2002 & 23.30 .22 & 2.4 & 1.7 & 27.10 .2002 & 03.18 .15 & 2.8 & 2.2 \\
\hline 26.10 .2002 & 23.46 .34 & 2.4 & 2.0 & 27.10 .2002 & 03.28 .55 & 2.8 & 3.5 \\
\hline 26.10 .2002 & 23.49 .42 & 2.4 & 1.8 & 27.10 .2002 & 03.53 .26 & 2.5 & 3.3 \\
\hline 27.10.2002 & 00.12 .57 & 2.3 & 1.4 & 27.10.2002 & 04.13 .12 & 2.4 & 3.1 \\
\hline 27.10 .2002 & 00.13 .19 & 2.6 & 2.6 & 27.10 .2002 & 04.17 .07 & 2.9 & 3.8 \\
\hline 27.10 .2002 & 00.13 .29 & 3.0 & 2.8 & 27.10 .2002 & 05.02 .04 & 2.5 & 3.1 \\
\hline 27.10 .2002 & 00.16 .45 & 2.7 & 2.9 & 27.10 .2002 & 05.20 .57 & 2.6 & 3.2 \\
\hline 27.10 .2002 & 00.21 .11 & 2.4 & 2.1 & 27.10 .2002 & 05.25 .05 & 2.6 & 3.5 \\
\hline 27.10 .2002 & 00.21 .51 & 2.7 & 2.5 & 27.10 .2002 & 05.31 .11 & 3.3 & 4.2 \\
\hline 27.10 .2002 & 00.23 .49 & 2.5 & 2.4 & 27.10 .2002 & 05.46 .45 & 3.4 & 3.9 \\
\hline 27.10 .2002 & 00.26 .29 & 2.5 & 3.0 & 27.10 .2002 & 06.06 .55 & 3.4 & 3.4 \\
\hline 27.10 .2002 & 00.29 .39 & 3.1 & 3.4 & 27.10 .2002 & 06.26 .13 & 2.8 & 3.3 \\
\hline 27.10.2002 & 00.30 .39 & 3.2 & 2.8 & 27.10.2002 & 06.28 .14 & 2.9 & 3.8 \\
\hline 27.10 .2002 & 00.32 .38 & 2.9 & 3.7 & 27.10 .2002 & 06.49 .32 & 2.9 & 3.8 \\
\hline 27.10.2002 & 00.34 .12 & 3.1 & 3.4 & 27.10.2002 & 07.32 .06 & 3.2 & 4.4 \\
\hline 27.10 .2002 & 00.35 .03 & 3.0 & 3.3 & 27.10 .2002 & 08.04.32 & 2.8 & 3.4 \\
\hline 27.10 .2002 & 00.36 .09 & 3.1 & 2.4 & 27.10 .2002 & 10.07 .56 & 2.7 & 3.3 \\
\hline 27.10 .2002 & 00.41 .49 & 3.2 & 3.9 & 27.10 .2002 & 10.24 .48 & 2.7 & 3.4 \\
\hline 27.10.2002 & 01.01 .40 & 2.7 & 2.9 & 27.10.2002 & 11.03 .01 & 2.6 & 3.2 \\
\hline 27.10 .2002 & 01.07 .46 & 2.4 & 3.1 & 27.10 .2002 & 12.09 .58 & 2.7 & 2.9 \\
\hline 27.10.2002 & 01.08 .18 & 2.6 & 3.3 & 27.10.2002 & 12.16 .05 & 2.6 & 3.0 \\
\hline 27.10 .2002 & 01.11 .25 & 3.0 & 3.5 & 27.10 .2002 & 12.44 .21 & 2.3 & 3.1 \\
\hline 27.10 .2002 & 01.13 .32 & 3.3 & 3.9 & 27.10.2002 & 13.23 .56 & 2.7 & 3.3 \\
\hline 27.10 .2002 & 01.23 .48 & 3.0 & 3.8 & 27.10 .2002 & 13.34 .56 & 2.6 & 3.3 \\
\hline 27.10 .2002 & 01.26 .24 & 3.0 & 3.3 & 27.10 .2002 & 14.00 .44 & 2.7 & 3.8 \\
\hline 27.10.2002 & 01.28 .17 & 3.5 & 4.1 & 27.10.2002 & 14.42 .44 & 2.5 & 3.1 \\
\hline 27.10 .2002 & 01.29 .27 & 2.7 & 3.1 & 27.10 .2002 & 14.56 .29 & 2.7 & 3.4 \\
\hline 27.10 .2002 & 01.30 .30 & 2.8 & 3.3 & 27.10 .2002 & 15.51 .07 & 3.0 & 3.8 \\
\hline 27.10.2002 & 01.33 .24 & 2.6 & 2.7 & 27.10 .2002 & 15.56.17 & 2.8 & 3.2 \\
\hline 27.10 .2002 & 01.34 .25 & 2.4 & 2.6 & 27.10 .2002 & 16.02 .09 & 2.9 & 3.2 \\
\hline 27.10 .2002 & 01.36 .13 & 2.4 & 3.0 & 27.10 .2002 & 16.07 .46 & 2.6 & 2.9 \\
\hline
\end{tabular}


Appendix (continued).

\begin{tabular}{|c|c|c|c|c|c|c|c|}
\hline Time & Origin & $M_{D}$ & $M_{L}$ & Time & Origin & $M_{D}$ & $M_{L}$ \\
\hline 27.10.2002 & 16.47 .50 & 2.7 & 3.1 & 30.10 .2002 & 07.20 .06 & 2.5 & 1.8 \\
\hline 27.10.2002 & 22.04 .17 & 2.6 & 2.8 & 30.10 .2002 & 10.05 .38 & 2.2 & 2.0 \\
\hline 28.10 .2002 & 03.01 .40 & 3.2 & 4.0 & 30.10 .2002 & 10.06 .23 & 2.5 & 1.8 \\
\hline 28.10 .2002 & 09.12.37 & 3.2 & 2.8 & 30.10 .2002 & 10.47 .00 & 2.6 & 2.4 \\
\hline 28.10 .2002 & 11.40 .10 & 3.1 & 3.2 & 30.10 .2002 & 15.25 .43 & 3.2 & 3.3 \\
\hline 28.10 .2002 & 11.51.32 & 2.8 & 3.0 & 30.10 .2002 & 15.38 .37 & 2.6 & 2.5 \\
\hline 28.10 .2002 & 16.27 .04 & 3.0 & 3.2 & 30.10 .2002 & 21.13 .20 & 1.9 & 1.6 \\
\hline 28.10 .2002 & 23.25 .47 & 2.0 & 1.8 & 30.10 .2002 & 21.14 .42 & 2.5 & 2.1 \\
\hline 29.10 .2002 & 01.31 .46 & 2.6 & 2.7 & 30.10 .2002 & 21.15 .03 & 2.1 & 1.7 \\
\hline 29.10 .2002 & 02.32 .48 & 2.3 & 1.8 & 30.10 .2002 & 21.17.35 & 1.7 & 1.7 \\
\hline 29.10.2002 & 07.22 .33 & 2.6 & 2.4 & 30.10 .2002 & 21.18 .34 & 1.5 & 1.6 \\
\hline 29.10 .2002 & 07.27 .14 & 2.6 & 2.0 & 31.10 .2002 & 00.44 .54 & 1.8 & 1.8 \\
\hline 29.10.2002 & 08.34 .33 & 2.9 & 3.5 & 31.10 .2002 & 06.51 .40 & 1.9 & 1.5 \\
\hline 29.10 .2002 & 09.56 .49 & 2.0 & 1.8 & 31.10 .2002 & 10.41 .04 & 3.2 & 2.8 \\
\hline 29.10 .2002 & 10.02 .09 & 3.0 & 2.8 & 31.10 .2002 & 11.22 .12 & 2.4 & 2.2 \\
\hline 29.10 .2002 & 10.02 .20 & 4.4 & 3.7 & 31.10 .2002 & 18.07.22 & 2.7 & 2.4 \\
\hline 29.10.2002 & 10.04 .41 & 3.1 & 3.1 & 31.10 .2002 & 18.50 .10 & 2.1 & 1.8 \\
\hline 29.10 .2002 & 10.12 .51 & 2.4 & 2.3 & 31.10 .2002 & 20.22.20 & 2.0 & 2.2 \\
\hline 29.10.2002 & 10.13 .25 & 2.8 & 2.8 & 01.11 .2002 & 01.29 .51 & 2.5 & 2.2 \\
\hline 29.10 .2002 & 10.17.37 & 2.5 & 2.5 & 01.11 .2002 & 05.16 .37 & 2.7 & 2.2 \\
\hline 29.10.2002 & 10.18 .48 & 2.1 & 2.2 & 01.11 .2002 & 15.32 .03 & 3.1 & 2.9 \\
\hline 29.10 .2002 & 10.34 .58 & 2.9 & 2.9 & 02.11 .2002 & 10.06 .55 & 2.0 & 2.0 \\
\hline 29.10.2002 & 10.56 .09 & 3.6 & 3.5 & 02.11 .2002 & 17.09 .54 & 2.8 & 2.3 \\
\hline 29.10.2002 & 10.59 .42 & 2.1 & 2.0 & 02.11 .2002 & 23.08 .16 & 2.5 & 2.4 \\
\hline 29.10.2002 & 11.02 .00 & 4.0 & 3.4 & 03.11 .2002 & 00.22 .30 & 2.3 & 2.1 \\
\hline 29.10 .2002 & 11.20 .06 & 1.9 & 1.6 & 03.11 .2002 & 05.32 .22 & 1.4 & 1.6 \\
\hline 29.10 .2002 & 11.22 .04 & 1.7 & 1.5 & 03.11 .2002 & 05.35 .14 & 2.1 & 1.8 \\
\hline 29.10 .2002 & 11.32 .42 & 1.9 & 2.2 & 03.11 .2002 & 05.36 .02 & 2.5 & 2.1 \\
\hline 29.10.2002 & 11.51 .40 & 2.7 & 2.3 & 03.11 .2002 & 10.21 .59 & 3.5 & 3.4 \\
\hline 29.10 .2002 & 12.21 .57 & 2.1 & 2.2 & 03.11 .2002 & 13.03 .09 & 2.7 & 4.2 \\
\hline 29.10 .2002 & 13.25 .31 & 2.7 & 2.7 & 03.11 .2002 & 13.43 .40 & 2.2 & 2.0 \\
\hline 29.10.2002 & 15.49 .50 & 3.8 & 3.6 & 04.11 .2002 & 02.49 .52 & 2.7 & 2.3 \\
\hline 29.10 .2002 & 16.39 .46 & 4.0 & 4.1 & 04.11 .2002 & 05.29 .55 & 1.9 & 1.7 \\
\hline 29.10.2002 & 17.14 .00 & 4.1 & 3.5 & 04.11 .2002 & 08.47 .43 & 2.5 & 2.4 \\
\hline 29.10 .2002 & 19.07 .48 & 1.7 & 1.6 & 04.11 .2002 & 10.52 .35 & 3.0 & 2.7 \\
\hline 29.10 .2002 & 20.35 .16 & 2.0 & 1.7 & 04.11 .2002 & 10.54 .20 & 3.1 & 3.1 \\
\hline 29.10 .2002 & 22.24 .47 & 2.8 & 2.4 & 05.11 .2002 & 18.54 .47 & 2.7 & 2.4 \\
\hline 30.10 .2002 & 00.00 .13 & 3.1 & 2.9 & 05.11 .2002 & 19.00 .13 & 2.8 & 2.4 \\
\hline 30.10 .2002 & 02.16 .17 & 2.0 & 2.1 & 07.11 .2002 & 09.03 .18 & 2.3 & 1.9 \\
\hline 30.10 .2002 & 02.20 .28 & 2.5 & 2.5 & 07.11 .2002 & 15.07.49 & 2.4 & 2.1 \\
\hline
\end{tabular}


Appendix (continued).

\begin{tabular}{|c|c|c|c|c|c|c|c|}
\hline Time & Origin & $M_{D}$ & $M_{L}$ & Time & Origin & $M_{D}$ & $M_{L}$ \\
\hline 07.11 .2002 & 16.35 .30 & 2.6 & 2.1 & 13.02 .2003 & 06.53 .43 & 2.9 & 2.0 \\
\hline 14.11.2002 & 03.31 .10 & 2.8 & 2.6 & 13.02 .2003 & 16.15 .32 & 1.7 & 0.5 \\
\hline 16.11.2002 & 23.19 .43 & 2.7 & 2.7 & 13.02 .2003 & 17.55.36 & 1.7 & 0.6 \\
\hline 17.11.2002 & 09.26.21 & 2.8 & 2.8 & 14.02 .2003 & 04.44 .11 & 2.6 & 1.8 \\
\hline 17.11.2002 & 09.56 .18 & 2.9 & 2.9 & 14.02 .2003 & 05.24 .03 & 1.5 & 0.9 \\
\hline 19.11.2002 & 10.42 .03 & 2.6 & 2.5 & 15.02 .2003 & 19.11.33 & 1.5 & 0.7 \\
\hline 24.11.2002 & 06.55 .55 & 2.7 & 3.0 & 16.02 .2003 & 12.55 .09 & 2.2 & 1.6 \\
\hline 24.11.2002 & 07.38.29 & 2.8 & 2.5 & 17.02.2003 & 01.30 .43 & 2.5 & 1.9 \\
\hline 24.11.2002 & 10.27 .36 & 2.5 & 2.5 & 18.02.2003 & 18.17.36 & 1.3 & 0.6 \\
\hline 24.11.2002 & 11.03 .36 & 3.0 & 2.9 & 18.02 .2003 & 22.15 .06 & 2.6 & 1.9 \\
\hline 24.11.2002 & 13.56 .23 & 2.7 & 2.6 & 18.02.2003 & 22.16 .14 & 1.6 & 0.9 \\
\hline 24.11.2002 & 14.53 .02 & 2.8 & 3.0 & 21.02 .2003 & 13.46 .23 & 2.0 & 0.9 \\
\hline 24.11.2002 & 15.40 .12 & 2.6 & 1.9 & 21.02 .2003 & 14.36 .11 & 1.5 & 0.8 \\
\hline 02.12 .2002 & 12.20 .38 & 2.8 & 2.9 & 22.02 .2003 & 01.08 .39 & 2.0 & 1.0 \\
\hline 03.12 .2002 & 13.50 .25 & 3.0 & 2.9 & 23.02 .2003 & 01.58 .45 & 2.1 & 1.5 \\
\hline 03.12 .2002 & 21.07 .00 & 2.8 & 3.2 & 26.02.2003 & 18.35.02 & 2.1 & 1.6 \\
\hline 05.12 .2002 & 00.40 .34 & 2.6 & 2.2 & 01.03 .2003 & 21.10 .35 & 2.4 & 1.3 \\
\hline 05.01 .2003 & 15.38 .56 & 2.1 & 1.7 & 02.03 .2003 & 11.55 .07 & 1.4 & 1.1 \\
\hline 20.01.2003 & 06.46 .43 & 2.3 & 1.9 & 03.03 .2003 & 20.48 .44 & 1.5 & 1.1 \\
\hline 20.01.2003 & 21.26 .50 & 1.9 & 2.0 & 03.03 .2003 & 20.49 .23 & 1.4 & 0.7 \\
\hline 21.01.2003 & 00.51 .30 & 1.6 & 1.5 & 03.03 .2003 & 20.58 .14 & 2.4 & 2.4 \\
\hline 25.01.2003 & 03.29 .18 & 2.7 & 2.5 & 03.03 .2003 & 21.02 .48 & 2.6 & 2.0 \\
\hline 25.01.2003 & 08.37 .13 & 2.3 & 1.8 & 04.03 .2003 & 05.34 .33 & 1.5 & 0.6 \\
\hline 30.01 .2003 & 20.25 .06 & 1.5 & 0.6 & 04.03 .2003 & 05.38 .06 & 1.5 & 0.6 \\
\hline 01.02 .2003 & 04.32 .25 & 1.5 & 1.0 & 05.03 .2003 & 08.07 .42 & 1.4 & 0.5 \\
\hline 01.02 .2003 & 09.20 .03 & 2.1 & 1.2 & 05.03 .2003 & 08.09 .53 & 2.2 & 1.6 \\
\hline 01.02 .2003 & 10.52 .08 & 2.0 & 1.5 & 08.03.2003 & 04.56 .12 & 2.0 & 1.3 \\
\hline 02.02.2003 & 02.32 .51 & 1.4 & 1.1 & 09.03.2003 & 07.55.59 & 3.0 & 3.0 \\
\hline 02.02 .2003 & 19.47.32 & 1.2 & 0.7 & 09.03.2003 & 07.57 .25 & 2.5 & 2.1 \\
\hline 08.02.2003 & 19.37.09 & 2.0 & 0.8 & 09.03.2003 & 08.00 .05 & 2.3 & 1.9 \\
\hline 09.02.2003 & 08.46 .10 & 2.7 & 1.8 & 09.03.2003 & 08.25 .36 & 2.5 & 2.1 \\
\hline 09.02.2003 & 13.26 .52 & 2.2 & 1.0 & 09.03.2003 & 08.28 .48 & 2.5 & 2.3 \\
\hline 10.02.2003 & 13.40 .07 & 2.5 & 1.9 & 09.03.2003 & 08.30 .27 & 2.1 & 1.7 \\
\hline 11.02.2003 & 00.43 .44 & 2.5 & 1.8 & 09.03.2003 & 08.31.31 & 2.2 & 1.6 \\
\hline 12.02 .2003 & 19.01.28 & 1.9 & 1.4 & 09.03.2003 & 08.55.21 & 2.2 & 1.7 \\
\hline 13.02.2003 & 05.29 .10 & 2.9 & 2.4 & 10.03 .2003 & 05.04 .53 & 2.5 & 1.6 \\
\hline 13.02.2003 & 05.32 .41 & 2.5 & 2.9 & 11.03 .2003 & 06.26 .44 & 1.7 & 0.9 \\
\hline 13.02.2003 & 05.33 .01 & 3.8 & 3.8 & 12.03 .2003 & 01.44 .39 & 1.2 & 1.5 \\
\hline 13.02.2003 & 05.44 .35 & 2.9 & 2.1 & 14.03 .2003 & 03.42 .31 & 2.9 & 2.5 \\
\hline 13.02.2003 & 05.48 .00 & 2.5 & 1.2 & 14.03 .2003 & 22.19 .26 & 1.8 & 1.8 \\
\hline
\end{tabular}


Appendix (continued).

\begin{tabular}{cccc|cccc}
\hline \hline Time & Origin & $M_{D}$ & $M_{L}$ & Time & Origin & $M_{D}$ & $M_{L}$ \\
\hline 15.03 .2003 & 00.14 .57 & 1.2 & 1.0 & 25.03 .2003 & 08.12 .00 & 2.3 & 2.1 \\
16.03 .2003 & 17.48 .45 & 1.9 & 1.0 & 25.03 .2003 & 12.28 .19 & 2.0 & 1.2 \\
16.03 .2003 & 21.58 .06 & 2.0 & 1.3 & 25.03 .2003 & 13.12 .53 & 2.1 & 1.6 \\
17.03 .2003 & 20.56 .27 & 1.0 & 0.5 & 25.03 .2003 & 14.08 .24 & 1.7 & 1.2 \\
18.03 .2003 & 01.49 .19 & 1.5 & 0.9 & 26.03 .2003 & 08.25 .48 & 2.0 & 1.3 \\
18.03 .2003 & 10.09 .33 & 1.6 & 1.0 & 26.03 .2003 & 10.30 .24 & 1.3 & 0.5 \\
18.03 .2003 & 18.14 .12 & 2.1 & 1.7 & 29.03 .2003 & 14.40 .29 & 1.5 & 0.9 \\
19.03 .2003 & 04.51 .11 & 1.5 & 1.0 & 29.03 .2003 & 16.22 .36 & 2.1 & 0.7 \\
19.03 .2003 & 15.42 .51 & 2.1 & 1.6 & 30.03 .2003 & 13.42 .30 & 1.3 & 0.8 \\
20.03 .2003 & 05.48 .07 & 1.3 & 0.7 & 30.03 .2003 & 13.48 .29 & 1.7 & 0.7 \\
21.03 .2003 & 15.29 .59 & 1.7 & 1.1 & 31.03 .2003 & 12.49 .13 & 2.5 & 1.9 \\
22.03 .2003 & 14.49 .12 & 2.1 & 1.5 & 01.04 .2003 & 13.26 .46 & 3.1 & 2.9 \\
23.03 .2003 & 04.02 .03 & 1.5 & 1.1 & 02.04 .2003 & 17.15 .31 & 1.8 & 0.9 \\
23.03 .2003 & 20.36 .39 & 2.0 & 1.4 & 05.04 .2003 & 19.19 .14 & 2.9 & 2.3 \\
25.03 .2003 & 03.57 .14 & 2.6 & 1.7 & 05.04 .2003 & 19.45 .27 & 2.1 & 1.3 \\
25.03 .2003 & 07.16 .10 & 2.5 & 2.3 & 05.04 .2003 & 20.35 .36 & 2.0 & 1.8 \\
\hline
\end{tabular}

\section{REFERENCES}

AzZARo, R. and A. MostaCcio (2003): $1^{\circ}$ Rapporto preliminare sul terremoto etneo del 29.10.2002 ore 11:02 (loc.), (on line: http://www.ct.ingv.it/report/Smmacro20021029.pdf).

AZZARO, R. and L. SCARFI (2003): $1^{\circ}$ Rapporto preliminare sul terremoto etneo del 29.10.2002 ore 18:15 (loc.), (on line: http://www.ct.ingv.it/report/Smmacro20021029c.pdf).

BAKun, W.H., S.T. HoucK and W.H.K. LEE (1978): A direct comparison of «synthetic» and actual Wood-Anderson seismograms, Bull. Seismol. Soc. Am., 68, 1199-1202.

Bath, M. (1974): Spectral Analysis in Geophysics (Elsevier, Amsterdam), pp. 563.

BRUnE, J.N. (1970): Tectonic stress and the spectra of seismic shear waves from earthquakes, Bull. Seismol. Soc. Am., 54, 1875-1888.

Caltabiano, T., D. Condarelli, S. Gresta, D. Patanè and G. PATANE (1986): Analisi preliminare dei dati della stazione sismica di Serra Pizzuta Calvarina, CNR IIV Open File Rep. 10/86.

Calvari, S., P. Del Carlo, S. Branca, D. Andronico, N. Bruno, M.R. Burton, T. Caltabiano, M. Cascone, M. Coltelli, D. Condarelli, R.A. Corsaro, A. Cristaldi, E. De Beni, G. Garfì, G. Lanzafame, L. Lodato, V. Longo, S. Mangiagli, L. Messina, L. Miraglia, F. Morabito, F. Muré, M. Neri, E. Pecora, M. Pompilio, G. Salerno, G. SAWyer, S. Scollo and L. SPAMPINATO (2004): The first period of the 2002 Etna eruption (27 October-5 November): preliminary results, Quad. Geofis., 32, 1-10.

Cardaci, C. and E. Privitera (1996): Applicazione di metodi per la stima della magnitudo ai terremoti locali registrati dalla rete sismica permanente dell'Etna, $C N R$ IIV Open File Rep. 3/96.

Del Pezzo, E. and S. Petrosino (2001): A local-magnitude scale for Mt. Vesuvius from syntheticWood-Anderson seismograms, J. Seismol., 5, 207-215.

Di Grazia, G., H. Langer, A. Ursino, L. Scarfì and S. GRESTA (2001): On the estimate of earthquake magnitude at a local seismic network, Ann. Geofis., 44 (3), 579-591.

GASPERINI, P. (2002): Local magnitude revaluation for recent Italian earthquakes (1981-1996), J. Seismol., 6, 503-524.

Giampiccolo, E., S. D’Amico, D. Patané and S. Gresta (2003). Attenuation of seismic waves and source parameters of shallow microearthquakes recorded at Mt. Etna volcano (Italy), in EGS-AGU-EUG Joint Assembly, 06-11 April 2003, Nice, France.

Hirn, A., A. Nercessian, M. Sapin, F. Ferrucci and G. WitTLINGER (1991): Seismic heterogeneity of Mt. Etna: structure and activity, Geophys. J. Int., 105, 139-153.

KANAMORI, H. and P.C. JeNNINGS (1978): Determination of local magnitude, $M_{L}$, from strong-motion accelerograms, Bull. Seismol. Soc. Am., 68, 471-485.

KeILIS-BoroK, V.I. (1957): On the estimation of the displacement in an earthquake source and of source dimensions, Ann. Geofis., XII, 205-214.

LAHR, J.C. (1999): Hypoellipse: a computer program for determining local earthquake hypocentral parameters, magnitude, and first motion pattern (Y2K compliant), U.S. Geol. Surv. Open File Rep. 99-23.

LAY, T. and T.C. Wallace (1995): Modern Global Seismol- 
ogy (Academic Press, San Diego, CA, U.S.A.).

LuCO, J.E. (1982): A note on near-source estimates of local magnitude, Bull Seismol. Soc. Am., 72, 941-958.

MEDNET (2003): MEDiterranean very broadband sismographic NETwork (on line: http://mednet.ingv.it).

REAL, C.R. and T.L. TENG (1973): Local Richter magnitude and total duration in Southern California, Bull. Seismol. Soc. Am., 63, 1809-1827.

RICHTER, C.F. (1935): An instrumental earthquake magnitude scale, Bull. Seismol. Am., 25, 1-32.

RICHTER, C.F. (1958): Elementary Seismology (Freeman, San Francisco, California), pp. 768.
Solov'Ev, S.L. (1965): Seismicity of Sakhalin, Bull Earthquakes Res. Inst., Tokyo Univ., 43, 95-102.

Tsumara, K. (1967): Determination of earthquake magnitude from total duration of oscillations, Bull. Earthquakes Res. Inst., Tokyo Univ., 53, 1-48.

URHAMmer, R.A. and E.H. Collins (1990): Synthesis of Wood-Anderson seismograms from broadband digital records, Bull. Seismol. Soc. Am., 80, 702-718.

(received December 18, 2003; accepted November 17, 2004) 